\title{
Piperidinolysis of 4-Nitrophenyl X-Substituted Benzenesulfonates and Related Compounds: Effect of Changing Leaving Group and Electrophilic Center
}

\author{
Ik-Hwan Um* and Kalsoom Akhtar \\ Department of Chemistry and Nano Science, Ewha Womans University, Seoul 120-750, Korea. ${ }^{*}$ E-mail: ihum@ewha.ac.kr \\ Received September 22, 2009, Accepted November 23, 2009
}

Key Words: Aryl benzenesulfonate, Substituent effect, Hammett plot, Yukawa-Tsuno plot, Ground-state stabilization

Aminolyses of carboxylic esters have generally been suggested to proceed through a stepwise mechanism. ${ }^{1-7}$ Curved Brønsted-type plots reported for aminolyses of esters possessing a good leaving group (e.g., 2,4-dinitrophenoxide) have been taken as evidence for a change in rate-determining step (RDS) of a stepwise mechanism. ${ }^{1-7} \mathrm{RDS}$ has been reported to be governed by the basicity of the incoming amine and the leaving group, e.g., RDS changes from breakdown of zwitterionic tetrahedral intermediate $\left(\mathrm{T}^{ \pm}\right)$to its formation as the incoming amine becomes more basic than the leaving group by 4 to $5 \mathrm{p} K_{\mathrm{a}}$ units. ${ }^{1-7}$

However, the effect of substituents in the nonleaving group on mechanism remains controversial. Jencks et al. have concluded that an electron withdrawing group (EWG) decreases the rate of leaving-group departure but increases expulsion of the amine from $\mathrm{T}^{ \pm}$in nucleophilic substitution reactions of diaryl carbonates with quinuclidines. ${ }^{8}$ Thus, an EWG has been suggested to decrease the $k_{2} / k_{-1}$ ratio. A similar conclusion has recently been drawn by Castro et al. for aminolysis of aryl 4-nitrophenyl carbonates and related compounds. ${ }^{4}$

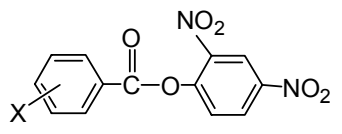

1

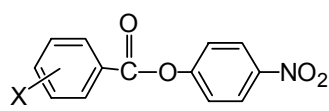

In contrast, we have shown that the $k_{2} / k_{-1}$ ratio is not influenced by the electronic nature of substituent in the nonleaving group in aminolyses of various types of esters. ${ }^{7 b, 9 b, 10 b, 16-18} \mathrm{We}$ found that the Hammett plots for aminolyses of 2,4-dinitrophenyl X-substituted benzoates (1a-e) and 4-nitrophenyl X-substituted benzoates (2a-h) consist of two intersecting straight lines, ${ }^{9}$ which might be interpreted as a change in RDS. However, it has been concluded that the nonlinear Hammett plots are not due to a change in RDS but are caused by stabilization of the ground state (GS) of the substrates through resonance interactions between an electron-donating group (EDG) and the carbonyl functionality as illustrated by resonance structures I and II. ${ }^{9 \mathrm{~b}}$ The evidence provided was the fact that the corresponding Yukawa-Tsuno plots exhibit excellent linear correlations. ${ }^{9 b}$

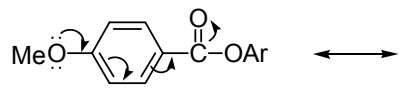

I

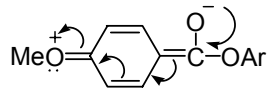

II
We reported that reactions of 2,4-dinitrophenyl X-substituted benzenesulfonates (3a-g) with a series of alicyclic secondary amines proceed through a stepwise mechanism with a change in RDS on the basis of a curved Brønsted-type plot. ${ }^{10 a}$ It has also been found that the Hammett plot for the reactions of (3a-g) with piperidine is nonlinear, i.e., the substrates possessing an EDG in the sulfonyl moiety exhibit negative deviations from the Hammett plot. ${ }^{10 a}$ In contrast, we have reported that the corresponding Yukawa-Tsuno plot is linear with $\rho_{\mathrm{X}}=0.79$ and $r=0.45$, indicating that the nonlinear Hammett plot is due to stabilization of the GS of substrate possessing an EDG as reported for aminolysis of aryl benzoates. ${ }^{7,5}$

$$
\mathrm{X}=4-\mathrm{NO}_{2}(\mathbf{3 a}), 4-\mathrm{Cl}(\mathbf{3 c}), \mathrm{H}(\mathbf{3 d}), 4-\mathrm{Me}(\mathbf{3 f}), 4-\mathrm{MeO}(\mathbf{3 g}) \text {. }
$$

Our study has been extended to the nucleophilic substitution reactions of 4-nitrophenyl X-substituted benzenesulfonates (4a-g) with piperidine (Scheme 1). The kinetic data have been compared with those reported previously ${ }^{10 \mathrm{a}}$ for the corresponding reactions of (3a-g) to investigate the effect of changing the leaving-group from 2,4-dinitrophenoxide to 4-nitrophenoxide. The data for the reactions of sulfonates (3a-g) and (4a-g) have been also compared with those reported previously for reactions of benzoates ${ }^{9 a, 9 b}(\mathbf{1 a - e})$ and (2a-h) to study the effect of changing the electrophilic center from $\mathrm{C}=\mathrm{O}$ to $\mathrm{O}=\mathrm{S}=\mathrm{O}$.

\section{Results and Discussion}

The kinetic study was performed under pseudo-first-order conditions with the concentration of piperidine maintained in excess relative to the substrate concentration. All reactions obeyed first-order kinetics with quantitative liberation of 4nitrophenoxide ion. Pseudo-first-order rate constants $\left(k_{\mathrm{obsd}}\right)$ were calculated from the equation $\ln \left(A_{\infty}-A_{\mathrm{t}}\right)=-k_{\mathrm{obsd}} t+C$. The plots of $k_{\text {obsd }} v s$. piperidine concentration were linear passing through the origin, indicating that general base catalysis by a second piperidine molecule is absent. Second-order rate constants $\left(k_{\mathrm{N}}\right)$ were determined from the slope of the linear plots. From replicate runs, it is estimated that the uncertainty in the 


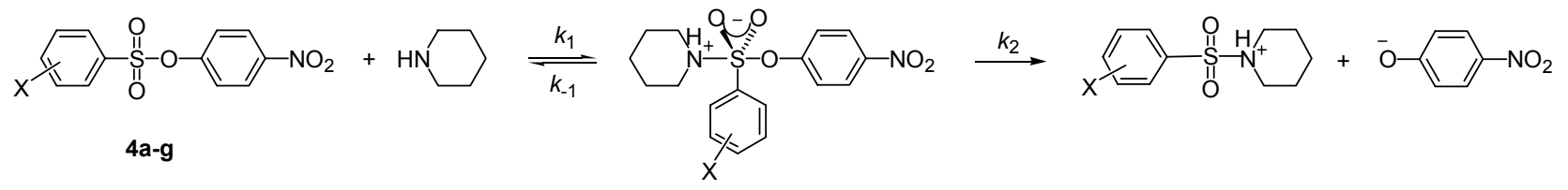

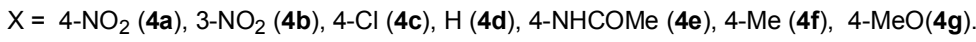

\section{Scheme 1}

Table 1. Summary of Second-order Rate Constants for Reactions of 2,4-Dinitrophenyl X-Substituted Benzenesulfonates (3a-g) and 4Nitrophenyl X-Substituted Benzenesulfonates (4a-g) with Piperidine in $80 \mathrm{~mol} \% \mathrm{H}_{2} \mathrm{O} / 20 \mathrm{~mol} \% \mathrm{DMSO}$ at $25.0 \pm 0.1{ }^{\circ} \mathrm{C}^{a}$

\begin{tabular}{clcc}
\hline \multirow{2}{*}{ Entry } & \multicolumn{1}{c}{$\mathrm{X}$} & \multicolumn{2}{c}{$10^{3} k_{\mathrm{N}} / \mathrm{M}^{-1} \mathrm{~s}^{-1}$} \\
\cline { 3 - 4 } & & $\mathbf{3}$ & $\mathbf{4}$ \\
\hline $\mathbf{a}$ & $4-\mathrm{NO}_{2}$ & 49900 & 6.65 \\
$\mathbf{b}$ & $3-\mathrm{NO}_{2}$ & - & 4.50 \\
$\mathbf{c}$ & $4-\mathrm{Cl}$ & 15100 & 1.54 \\
$\mathbf{d}$ & $\mathrm{H}$ & 11100 & 1.30 \\
$\mathbf{e}$ & $4-\mathrm{NHCOMe}$ & - & 0.699 \\
$\mathbf{f}$ & $4-\mathrm{Me}$ & 8200 & 0.675 \\
g & $4-\mathrm{MeO}$ & 5300 & 0.428 \\
\hline
\end{tabular}

${ }^{a}$ Data for the reactions of (3a-g) were taken from ref. 10a.

rate constant is less than $\pm 3 \%$. The $k_{\mathrm{N}}$ values determined are summarized in Table 1 together with those reported previously for the corresponding reactions of (3a-g) for comparison purpose.

Effect of nonleaving group substituent $X$ on reactivity. Table 1 shows that the second-order rate constant $\left(k_{\mathrm{N}}\right)$ for the reactions of (4a-g) decreases as the substituent X changes from a strong EWG to an EDG, e.g., $k_{\mathrm{N}}$ decreases from $6.65 \times 10^{-3}$ $\mathrm{M}^{-1} \mathrm{~s}^{-1}$ to $1.30 \times 10^{-3}$ and $4.28 \times 10^{-4} \mathrm{M}^{-1} \mathrm{~s}^{-1}$ as the substituent $\mathrm{X}$ changes from $4-\mathrm{NO}_{2}$ to $\mathrm{H}$ and $4-\mathrm{MeO}$, in turn. A similar result is shown for the corresponding reactions of (3a-g), although they are significantly more reactive than $(\mathbf{4 a - g})$.

The effect of substituent $X$ on reactivity is illustrated in Figures 1A and 1B. The Hammett plot correlated with $\sigma$ constants $(\mathrm{A})$ results in a poor correlation coefficient with $\rho_{\mathrm{X}}=$ 1.04. A similar result is obtained for the correlation with $\sigma^{+}$ constants (B), although the slope of the plot is much smaller (i.e., $\rho_{X}=0.72$ ). Accordingly, one cannot get any conclusive information about the substituent effect from the poorly correlated Hammett and Brown-Okamoto plots.

We have recently shown that Yukawa-Tsuno plots are highly effective to investigate substituent effect as well as to clarify ambiguities in reaction mechanism. ${ }^{10,11}$ Thus, Yukawa-Tsuno plots have been constructed in Figures 2A and 2B. Unlike the Hammett or Brown-Okamoto plot shown in Figures 1A and 1B, the Yukawa-Tsuno plot for the reactions of (4a-g) with piperidine results in an excellent linear correlation with $\rho_{\mathrm{X}}=$ 0.90 and $r=0.50$ (Figure 2A). The corresponding plot for the reactions of (3a-g) shown in Figure $2 \mathrm{~B}$ exhibits also an excellent correlation with $\rho_{\mathrm{X}}=0.79$ and $r=0.45$. The effect of changing the leaving-group on the magnitude of $\rho_{\mathrm{X}}$ and $r$ will be discussed in the following section.
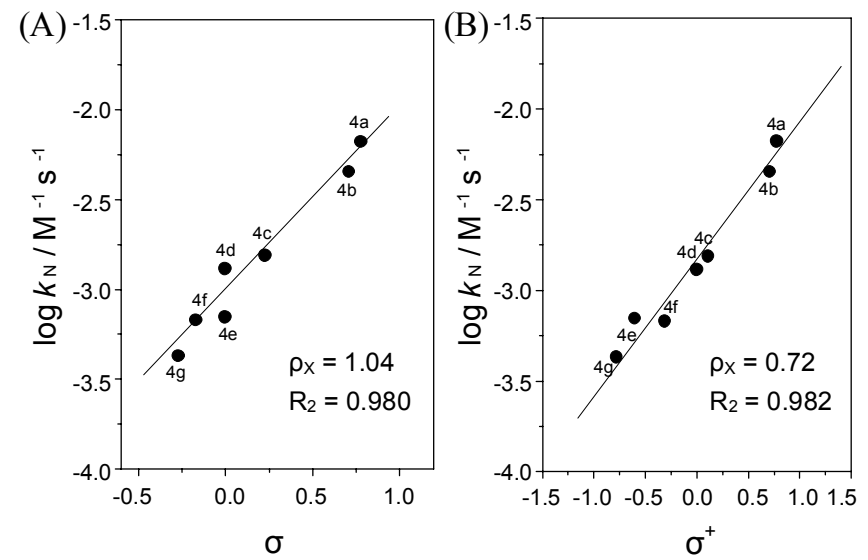

Figure 1. Hammett (A) and Brown-Okamoto (B) plots for piperidinolysis of 4-nitrophenyl $\mathrm{X}$-substituted phenyl benzenesulfonates (4a-g) in $80 \mathrm{~mol} \% \mathrm{H}_{2} \mathrm{O} / 20 \mathrm{~mol} \% \mathrm{DMSO}$ at $25.0 \pm 0.1{ }^{\circ} \mathrm{C}$. The identity of points is given in Table 1 .
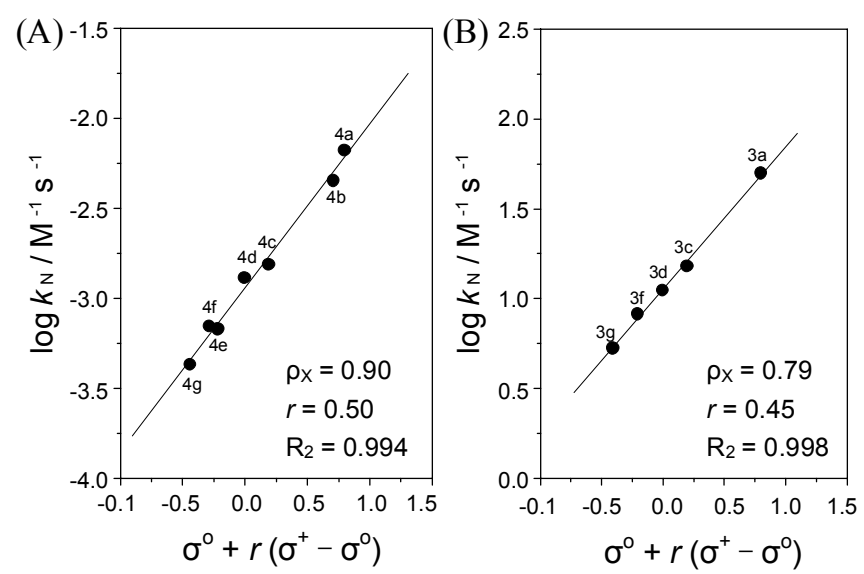

Figure 2. Yukawa-Tsuno plots for reactions of 4-nitrophenyl Xsubstituted phenyl benzenesulfonates, 4a-g (A) and 2,4-dinitrophenyl $\mathrm{X}$-substituted phenyl benzenesulfonates, 3a-g (B) with piperidine in $80 \mathrm{~mol} \% \mathrm{H}_{2} \mathrm{O} / 20 \mathrm{~mol} \% \mathrm{DMSO}$ at $25.0 \pm 0.1{ }^{\circ} \mathrm{C}$. The identity of points is given in Table 1.

The $r$ value in the Yukawa-Tsuno equation, eq. (1), represents the resonance demand of the reaction center or the extent of the resonance contribution, where as the term $\left(\sigma^{+}-\sigma^{\circ}\right)$ represents the resonance substituent constant that measures the capacity for $\pi$-delocalization of a given $\pi$-electron donor substituent. ${ }^{12,13}$ Eq. (1) becomes the Hammett equation when $r=0$ or the Brown-Okamoto equation when $r=1.0$. Since the $r$ value for the reactions of (4a-g) is neither 0 nor 1, the Yukawa-Tsuno plot results in a much better correlation coefficient than the 
plot correlated with $\sigma$ or $\sigma^{+}$constants.

$$
\log \left(k_{\mathrm{N}}^{\mathrm{X}} / k_{\mathrm{N}}{ }^{\mathrm{H}}\right)=\rho_{\mathrm{X}}\left[\sigma^{\circ}+r\left(\sigma^{+}-\sigma^{\circ}\right)\right]
$$

The Yukawa-Tsuno equation was derived to account for solvolyses of benzylic systems in which a positive charge develops partially in the transition state. ${ }^{12}$ Since such positive charge can be stabilized by an EDG in the benzylic moiety, negative $\rho_{x}$ values were obtained. However, the $\rho_{\mathrm{X}}$ value in this study is positive, indicating that an EDG in the sulfonyl moiety retards the reaction by stabilizing the GS of substrates as illustrated in the resonance structures III and IV.

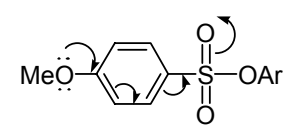

III

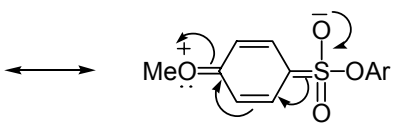

IV
Effect of changing electrophilic center from $\mathrm{C}=\mathrm{O}$ to $\mathrm{SO}_{2}$ on $\rho_{\mathrm{X}}$ and $\boldsymbol{r}$ values. As shown in Figures $2 \mathrm{~A}$ and $2 \mathrm{~B}$, the reactions of less reactive (4a-g) result in a slightly larger $\rho_{X}$ value than those of more reactive (3a-g) (i.e., $\rho_{X}=0.90$ for $\mathbf{4 a - g}$ and $\rho_{X}=$ 0.79 for 3a-g), which appears to be in accord with the reactivity-selectivity principle. ${ }^{15}$ It is noted that the $r$ value is also slightly larger for the reactions of $(\mathbf{4 a - g})(r=0.50)$ than for those of (3a-g) $(r=0.45)$. Both $\rho_{\mathrm{X}}$ and $r$ values are larger for the reactions of the less reactive substrates, $(\mathbf{4 a - g})$. This contrasts to our previous reports that $\rho_{\mathrm{X}}$ decreases linearly as $r$ increases for aminolyses of carboxylic esters. ${ }^{9 \mathrm{~b}, 10}$

Another interesting finding is that the $\rho_{\mathrm{X}}$ and $r$ values vary only slightly upon changing the leaving group of the sulfonate esters, i.e., as shown in Figure 2, $\rho_{\mathrm{X}}$ increases from 0.79 to 0.90 while the $r$ value varies from 0.45 to 0.50 as the leaving group changes from 2,4-dinitrophenoxide to 4-nitrophenoxide. In contrast, the $\rho_{\mathrm{X}}$ and $r$ values have been reported to change significantly upon changing the leaving group for the corresponding reactions of the benzoate esters, i.e., $\rho$ decreases from 1.46 to 0.75 while the $r$ increases from 0.36 to 0.75 as the leaving group changes from 2,4-dinitrophenoxide to 4-nitrophenoxide. $^{7 \mathrm{~b}, 9 \mathrm{~b}}$

The magnitude of $\rho_{\mathrm{X}}$ values represents a sensitivity parameter. On the other hand, the $r$ value in this study represents the degree of resonance contribution between an EDG and the sulfonyl functionality in the GS of the substrates (e.g., resonance structures III and IV). ${ }^{12,13}$ The difference in size and hybridization type of the two electrophilic centers (e.g., $\mathrm{SO}_{2}$ vs. $\mathrm{C}=\mathrm{O}$ ) is considered to be responsible for the contrasting behaviors found for the $\rho_{\mathrm{X}}$ and $r$ values in the reactions of the sulfonates and benzoates. The $\mathrm{sp}^{3}$ hybridized sulfur in the sulfonyl group is much larger than the $\mathrm{sp}^{2}$ hybridized carbonyl carbon. Accordingly, one might expect that the electronic effect of the $\mathrm{NO}_{2}$ group at the 2-position of the leaving aryloxide would be shielded more significantly for sulfonates (3a-g) than for benzoates (1a-e). This idea is consistent with the fact that the effect of changing the leaving group from 2,4-dinitrophenoxide to 4-nitrophenoxide on the $\rho_{\mathrm{X}}$ and $r$ values is much smaller for the reactions of the sulfonates than for those of the benzoates.

\section{Experimental Section}

Materials. Compounds (4a-g) were prepared readily from the reactions of X-substituted benzenesulfonyl chloride with 4nitrophenol in anhydrous ether in the presence of triethylamine as reported previously. ${ }^{10,14}$ Their purity was checked by means of $\mathrm{mp}$ and ${ }^{1} \mathrm{H} \mathrm{NMR}$ spectra. Other chemicals including piperidine used were of the highest quality available. Doubly glass distilled water was further boiled and cooled under nitrogen just before use to remove dissolved carbon dioxide.

Kinetics. The kinetic study was performed with a UV-vis spectrophotometer equipped with a constant temperature circulating bath to maintain the temperature in the reaction cell at $25.0 \pm 0.1{ }^{\circ} \mathrm{C}$. The reaction was followed by monitoring the appearance of the leaving 4-nitrophenoxide ion at $410 \mathrm{~nm}$. All the reactions were carried out under pseudo-first-order conditions in which the piperidine concentration was at least 30 times greater than the substrate concentration. The piperidine stock solution of $c a .0 .2 \mathrm{M}$ was prepared in a $25.0 \mathrm{~mL}$ vol. flask by adding 2 equiv. of piperidine to 1 equiv. of standardized $\mathrm{HCl}$ solution to obtain a self-buffered solution. All solutions were prepared freshly just before use under nitrogen and transferred by gas-tight syringes. Due to low solubility of (4a-g) in pure water, reactions were performed in $80 \mathrm{~mol} \% \mathrm{H}_{2} \mathrm{O} / 20$ mol \% DMSO.

Product analysis. 4-Nitrophenoxide was liberated quantitatively and identified as one of the products by comparison of the UV-vis spectrum at the end of the reaction with the authentic sample under the experimental condition.

Acknowledgments. This work was supported by a grant from Korea Research Foundation (KRF-2008-314-C00207). $\mathrm{K}$. Akhtar is also grateful to Korea Research Foundation for the Predominant Foreign Student Scholarship (KRF-2007211-C00021).

\section{References}

1. Jencks, W. P. Chem. Rev. 1985, 85, 511-527. (b) Page, M. I.; Williams, A. Organic and Bio-organic Mechanisms; Longman: Harlow, U.K., 1997; Chapter 7. (c) Jencks, W. P. Chem. Soc. Rev. 1981, 10, 345-375. (d) Satterthwait, A. C.; Jencks, W. P. J. Am. Chem. Soc. 1974, 96, 7018-7031. (e) Jencks, W. P. Catalysis in Chemistry and Enzymology; McGraw-Hill: New York, 1969; pp 480-483. (f) Jencks, W. P.; Gilchrist, M. J. Am. Chem. Soc. 1968, 90, 2622-2637

2. (a) Tsang, W. Y.; Ahmad, N.; Page, M. I. Org. Biomol. Chem. 2007, 5, 485-493. (b) Williams, A. Adv. Phys. Org. Chem. 1992, 27, 2-55. (c) Menger, F. M.; Smith, J. H. J. Am. Chem. Soc. 1972, 94, 3824-3829.

3. (a) Kovach, I. M.; Belz, M.; Larson, M.; Rousy, S.; Schowen, R. L. J. Am. Chem. Soc. 1985, 107, 7360-7365. (b) Neuvonen, H. J. Chem. Soc., Perkin Trans. 1987, 2, 159-167. (c) Knowlton, R. C.; Byers, L. D. J. Org. Chem. 1988, 53, 3862-3865.

4. (a) Castro, E. A. Pure. Appl. Chem. 2009, 81, 685-696. (b) Castro, E. A.; Gazitua, M.; Rios, P.; Tobar, P.; Santos, J. G. J. Phys. Org. Chem. 2009, 22, 443-448. (c) Castro, E. A.; Acuna, M.; Soto, C.; Trujillo, C.; Vasquez, B.; Santos, J. G. J. Phys. Org. Chem. 2008, 21, 816-822. (d) Castro, E. A.; Soto, C.; Vasquez, B.; Santos, J. G. 
ARKIVOC 2008, 151-160. (e) Castro, E. A.; Aliaga, M.; Santos, J. G. J. Phys. Org. Chem. 2008, 21, 271-278. (f) Castro, E. A.; Echevarria, G. R.; Opazo, A.; Robert, P.; Santos, J. G. J. Phys. Org. Chem. 2006, 19, 129-135.

5. (a) Lee, I.; Lee, H. W.; Yu, Y. K. Bull. Korean Chem. Soc. 2003, 24, 993-998. (b) Koh, H. J.; Han, K. L.; Lee, H. W.; Lee, I. J. Org. Chem. 2000, 65, 4706-4711.

6. (a) Sung, D. D.; Koo, I. S.; Yang, K. Y.; Lee, I. Chem. Phys. Lett. 2006, 432, 426-430. (b) Sung, D. D.; Koo, I. S.; Yang, K. Y.; Lee, I. Chem. Phys. Lett. 2006, 426, 280-284. (c) Oh, H. K.; Oh, J. Y.; Sung, D. D.; Lee, I. J. Org. Chem. 2005, 70, 5624-5629. (d) Oh, H. K.; Park, J. E.; Sung, D. D.; Lee, I. J. Org. Chem. 2004, 69, 3150-3153.

7. (a) Um, I. H.; Yoon, S.; Park, H. R.; Han, H. J. Org. Biomol. Chem. 2008, 6, 1618-1624. (b) Um, I. H.; Park, Y. M.; Fujio, M.; Mishima, M.; Tsuno, Y. J. Org. Chem. 2007, 72, 4816-4821. (c) Um, I. H.; Lee, J. Y.; Fujio, M.; Tsuno, Y. Org. Biomol. Chem. 2006, 4, 2979-2985. (d) Um, I. H.; Jeon, S. E.; Seok, J. A. Chem. Eur. J. 2006, 12, 1237-1243. (e) Um, I. H.; Kim, K. H.; Park, H. R.; Fujio, M.; Tsuno, Y. J. Org. Chem. 2004, 69, 3937-3942. (f) Um, I. H.; Lee, S. E.; Kwon, H. J. J. Org. Chem. 2002, 67, 8999-9005

8. Gresser, M. J.; Jencks, W. P. J. Am. Chem. Soc. 1977, 99, 69636970.

9. (a) Um, I. H.; Min, J. S.; Lee, H. W. Can. J. Chem. 1999, 77, 659-666. (b) Um, I. H.; Min, J. S.; Ahn, J. A.; Hahn, H. J. J. Org. Chem. 2000, 65, 5659-5663.
10. (a) Um, I. H.; Chun, S. M.; Chae, O. M.; Fujio, M.; Tsuno, Y. J. Org. Chem. 2004, 69, 3166-3172. (b) Um, I. H.; Lee, J. Y.; Lee, H. W.; Nagano, Y.; Fujio, M.; Tsuno, Y. J. Org. Chem. 2005, 70, 4980-4987.

11. (a) Um, I. H.; Akhtar, K.; Shin, Y. H.; Han, J. Y. J. Org. Chem. 2007, 72, 3823-3829. (b) Um, I. H.; Shin, Y. H.; Han, J. Y.; Mishima, M. J. Org. Chem. 2006, 71, 7715-7720. (c) Um, I. H.; Jeon, S. E.; Seok, J. A. Chem. Eur. J. 2006, 12, 1237-1243.

12. (a) Tsuno, Y.; Fujio, M. Adv. Phys. Org. Chem. 1999, 32, 267-385. (b) Tsuno, Y.; Fujio, M. Chem. Soc. Rev. 1996, 25, 129-139. (c) Yukawa, Y.; Tsuno, Y. Bull. Chem. Soc. Jpn. 1959, 32, 965-970.

13. (a) Fujio, M.; Umezaki, Y.; Alam, M. A.; Kikukawa, K.; Fujiyama, R.; Tsuno, Y. Bull. Chem. Soc. Jpn. 2006, 79, 1091-1099. (b) Fujio, M.; Uchida, M.; Okada, A.; Alam, M. A.; Fujiyama, R.; Siehl, H. U.; Tsuno, Y. Bull. Chem. Soc. Jpn. 2005, 78, 1834-1842. (c) Fujio, M.; Rappoport, Z.; Uddin, H. J.; Kim, H. J.; Tsuno, Y. Bull. Chem. Soc. Jpn. 2003, 76, 163-169. (d) Nakata, K.; Fujio, M.; Nishimoto, K.; Tsuno, Y. J. Phys. Org. Chem. 2003, 16, 323-335.

14. Um, I. H.; Hong, J. Y.; Kim, J. J.; Chae, O. M.; Bae, S. K. J. Org. Chem. 2003, 68, 5180-5185.

15. Pross, A. Adv. Phys. Org. Chem. 1977, 14, 69-132.

16. Um, I. H.; Chun, S. M.; Akhtar, K. Bull. Korean Chem. Soc. 2007, $28,220-224$

17. Um, I. H.; Hwang, S. J.; Baek, M. H.; Park, E. J. J. Org. Chem. 2006, 71,9191-9197.

18. Um, I. H.; Lee, J. Y.; Ko, S. H.; Bae, S. K. J. Org. Chem. 2006, $71,5800-5803$ 